\title{
Correction to: An Enhanced Cooperative Communication Scheme for Physical Uplink Shared Channel in NB-IoT
}

\author{
Mona Bakri Hassan ${ }^{1}$. Sameer Alsharif ${ }^{2} \cdot$ Hesham Alhumyani ${ }^{2}$. Elmustafa Sayed Ali $^{1}$. \\ Rania A. Mokhtar ${ }^{2} \cdot$ Rashid A. Saeed ${ }^{2}$ (I) \\ Published online: 12 February 2021 \\ ๑) Springer Science+Business Media, LLC, part of Springer Nature 2021
}

\section{Correction to: Wireless Personal Communications https://doi.org/10.1007/s11277-021-08067-1}

There were errors in the first and fourth authors' names in the initial online publication. The original article has been corrected.

Publisher's Note Springer Nature remains neutral with regard to jurisdictional claims in published maps and institutional affiliations.

The original article can be found online at https://doi.org/10.1007/s11277-021-08067-1.

Rashid A. Saeed

abdulhaleem@tu.edu.sa

1 Department of Electronics Engineering, Sudan University of Science and Technology (SUST),

1111 Khartoum, Sudan

2 Department of Computer Engineering, Taif University (TU), P.O. Box 11099, Taif 21944,

Saudi Arabia 